03

\title{
Сравнение плазменного и теплового воздействий на сверхзвуковое обтекание аэродинамического тела
}

\author{
(C) О.А. Азарова ${ }^{1}$, А.В. Ерофреев ${ }^{2}$, Т.А. Лапушкина ${ }^{2}$
}

${ }^{1}$ Вычислительный центр им. А.А. Дородницына Федерального исследовательского центра „Информатика и управление“ РАН, Москва

${ }^{2}$ Физико-технический институт им. А.Ф. Иоффе РАН, Санкт-Петербург

E-mail: tanyusha@mail.ioffe.ru

Поступило в Редакцию 8 декабря 2016 г.

Рассмотрена задача изменения параметров сверхзвукового обтекания полуцилиндрического тела. Экспериментально исследовано плазменное воздействие на процесс обтекания путем газоразрядного увеличения степени неравновесности набегающего потока. Для параметров потока, принятых в эксперименте, проведено численное моделирование теплового воздействия на ударный слой однородной нагретой области с температурой газа, равной температуре электронов, измеренной в эксперименте. Сравнение полученных экспериментальных и расчетных данных позволило сделать вывод о возможном новом механизме управления сверхзвуковым потоком, связанном с повышением степени неравновесности газа в источнике энергии.

DOI: 10.21883/PJTF.2017.08.44540.16598

Задачи управления параметрами сверхзвукового течения и ударноволновыми конфигурациями при помощи наложения электрического и магнитного полей исследовались экспериментально в работах [1-5]. Было показано, что возможно управление положением ударных волн, аэродинамическим сопротивлением, а также подъемной силой при помощи плазменного [1], теплового и магнитогидродинамического [2,3] воздействий.

В работе [1] были получены экспериментальные данные по плазменному воздействию на процесс обтекания полуцилиндрического тела. Для этой цели перед телом зажигался газовый разряд путем подачи токового импульса на электроды, вмонтированные в верхнюю и нижнюю стенки канала; тем самым создавалась газоразрядная область в набегающем на тело сверхзвуковом неравновесном потоке с начальной темпера- 
турой электронов $T_{e}=4640 \mathrm{~K}$ и температурой газа $T_{\infty}=1600 \mathrm{~K}$. Время разряда было подобрано так, чтобы энергия от джоулева нагрева в разряде не успевала передаваться тяжелой компоненте газа, а поступала только в нагрев электронов. За счет этого в натекающей на тело газоразрядной области увеличивалась степень неравновесности газа (ксенона), равная отношению температуры электронов к температуре газа. Проводилось варьирование ширины области воздействия путем подключения разного количества электродных пар и интенсивности газового разряда за счет изменения величины газоразрядного тока. Было обнаружено сильное влияние неравновесной плазмы на положение и устойчивость головной ударной волны, причем при увеличении температуры электронов увеличивался и отход волны от тела вплоть до полного ее разрушения.

Основной целью данной работы являлось выявление различий плазменного воздействия на параметры обтекания, связанного со степенью неравновесности газа, и теплового воздействия равновесной однородной горячей области потока. Для этой цели проводился расчет течения в предположении равновесия, когда температура горячей области $T_{i}$ равняется температуре электронов $T_{e}$ (что является верхним пределом возможного нагрева газа). Предполагалось, что сравнение двух воздействий, плазменного и теплового, поможет определить решающий фактор воздействия.

Моделирование взаимодействия полуограниченной тепловой области с ударным слоем около цилиндрически затупленной пластины проводилось при параметрах потока, получаемых в эксперименте (см. таблицу). Здесь приведены также нормирующие величины для рассмотрения задачи в безразмерном виде. Численно решалась система уравнений Эйлера в безразмерном виде для идеального равновесного газа с постоянным отношением удельных теплоемкостей $\gamma$ :

$$
\begin{gathered}
\frac{\partial \mathbf{U}}{\partial t}+\frac{\partial \mathbf{F}}{\partial x}+\frac{\partial \mathbf{G}}{\partial y}=0, \\
\mathbf{U}=\left(\begin{array}{c}
\rho \\
\rho u \\
\rho v \\
E
\end{array}\right), \mathbf{F}=\left(\begin{array}{c}
\rho u \\
p+\rho u^{2} \\
\rho u v \\
u(E+p)
\end{array}\right), \mathbf{G}=\left(\begin{array}{c}
\rho v \\
\rho u v \\
p+\rho v^{2} \\
v(E+p)
\end{array}\right) .
\end{gathered}
$$

Здесь $\rho, p-$ плотность и давление газа, $u$ и $v-x$-я и $y$-я компоненты скорости, $\varepsilon=p /(\rho(\gamma-1)), E=\rho\left(\varepsilon+0.5\left(u^{2}+v^{2}\right)\right)$.

Письма в ЖТФ, 2017, том 43, вып. 8 
Параметры набегающего потока и обтекаемого тела

\begin{tabular}{l|c|c|c}
\hline \multicolumn{1}{c|}{ Параметр } & $\begin{array}{c}\text { Размерное } \\
\text { значение }\end{array}$ & $\begin{array}{c}\text { Безразмерное } \\
\text { значение }\end{array}$ & $\begin{array}{c}\text { Нормирующий } \\
\text { параметр }\end{array}$ \\
\hline Число Маха М & & $\begin{array}{c}4.3 \\
\text { Показатель адиабаты } \gamma\end{array}$ & \\
$\begin{array}{l}\text { Плотность } \rho_{\infty} \\
\text { Температура } T_{\infty}\end{array}$ & $\begin{array}{c}0.127 \mathrm{~kg} / \mathrm{m}^{3} \\
1600 \mathrm{~K}\end{array}$ & $\begin{array}{c}1.0 \\
\text { (кенон) }\end{array}$ & $\begin{array}{c}\rho_{n}=0.127 \mathrm{~kg} / \mathrm{m}^{3} \\
T_{n}=12570.427 \mathrm{~K} \\
p_{n}=1 \mathrm{~atm}\end{array}$ \\
Давление $p_{\infty}$ & $\begin{array}{c}9.73498 \mathrm{Torr} \\
0.12728 \mathrm{~atm}\end{array}$ & $\begin{array}{c}0.12728 \\
=1.01325 \cdot 10^{5} \mathrm{~Pa}\end{array}$ \\
$\begin{array}{l}\text { Диаметр тела } D \\
\text { Размер по оси } x\end{array}$ & $4 \cdot 10^{-2} \mathrm{~m}$ & 0.2 & $l_{n}=2 \cdot 10^{-1} \mathrm{~m}$ \\
источника энергии & $5 \cdot 10^{-2} \mathrm{~m}$ & 0.4 & $l_{n}=2 \cdot 10^{-1} \mathrm{~m}$ \\
Продолжительность & & & \\
действия источника & $28.297 \mu \mathrm{s}$ & 0.12637 & $t_{n}=233.910 \mu \mathrm{s}$ \\
энергии & & &
\end{tabular}

Постановка задачи следующая. Сначала проводится расчет установившегося поля течения для стационарного обтекания цилиндрически затупленной пластины с параметрами набегающего потока $\rho_{\infty}=1$, $p_{\infty}=0.12728, u_{\infty}=M c_{\infty}, v_{\infty}=0$ в ксеноне $(\gamma=1.66)$. Течение выходит на стационарный режим к моменту времени $t=0.7$. Отход ударной волны в стационарном режиме течения с точностью $6.5 \%$ согласуется с данными, приведенными в [6] (включая точность восстановления значения из рис. 3 работы [6]), а значения плотности и давления в точке торможения на теле отличаются от теоретических на 1.1 и $2.1 \%$ соответственно. В момент времени $t_{i}=0.701$ перед головной ударной волной возникает источник энергии в виде ограниченного по оси $x$ и неограниченного по оси $y$ вертикального теплового слоя, ширина которого равна двум диаметрам обтекаемого тела. Тепловой слой моделируется областью пониженной плотности $\rho_{i}=\alpha_{\rho} \rho_{\infty}$ (и повышенной температуры $T_{i}=T_{e}=\alpha_{\rho}^{-1} T_{\infty}$ ) с остальными параметрами, равными параметрам набегающего потока [7]. Источник энергии движется вместе с потоком и далее взаимодействует с головной ударной волной. Отметим, что воздействие тепловых областей на ударную волну и сверхзвуковой слой перед телом являлось ранее и остается в настоящее время обширной областью исследований с приложениями к классу

Письма в ЖТФ, 2017, том 43, вып. 8 
задач управления сверхзвуковым потоком [8-10], в том числе и для широкого диапазона изменения $\gamma[11]$.

В расчетах используются комплексно-консервативные разностные схемы второго порядка аппроксимации [12] на ортогональной шахматной сетке с одинаковыми шагами по пространству; на поперечный размер тела приходится 1000 узлов.

Динамика взаимодействия полубесконечной тепловой области с ударным слоем, инициированным цилиндрически затупленной пластиной для $\gamma=1.66$, представлена на рис. 1 (цифры на рисунках - безразмерные моменты времени, значения на осях рис. 1-3 представлены в безразмерном виде). Здесь и на рис. 2 , а $\alpha_{\rho}=0.345$, температура в источнике энергии $T_{i}=4640 \mathrm{~K}$. При взаимодействии передней границы теплового слоя возникает ударно-волновая конфигурация (рис. 1,a), которая в одномерном приближении описывается решением задачи о распаде разрыва [13]. От центра распада разрыва влево распространяются ударная волна и контактный разрыв, и вправо - волна разрежения. Достигая тела, волна разрежения понижает давление на нем вместе с силой фронтального сопротивления [8]. Дальнейшее понижение сопротивления связано с увеличением отхода головной ударной волны от тела вследствие ее движения внутри горячей области. Прохождение задней границы теплового слоя инициирует ударно-волновую конфигурацию другого известного вида (рис. $1, b$ ), когда вправо вместо волны разрежения распространяется вторая ударная волна [13].

Взаимодействие этих групп разрывов (и простых волн) воздействует на динамику параметров торможения и силу сопротивления фронтальной поверхности тела, а также на отход головной ударной волны (рис. 2,a). Видно, что все рассматриваемые параметры взаимосвязаны, и большая удаленность головной волны от тела соответствует большему падению параметров торможения и силы сопротивления. Были проведены систематические расчеты динамики параметров обтекания для различных температур газа в источнике энергии (на рис. 2, $b$ представлена динамика координаты головной ударной волны для рассматриваемых температур). На рис. 3 для рассматриваемых температур представлены минимальные значения координаты волны (кривая 1) и соответствующие минимальные значения силы сопротивления фронтальной поверхности тела (кривая 2).

В эксперименте течение является суперпозицией газодинамических эффектов, изложенных выше, и плазменного воздействия, связанного с

Письма в ЖТФ, 2017, том 43, вып. 8 

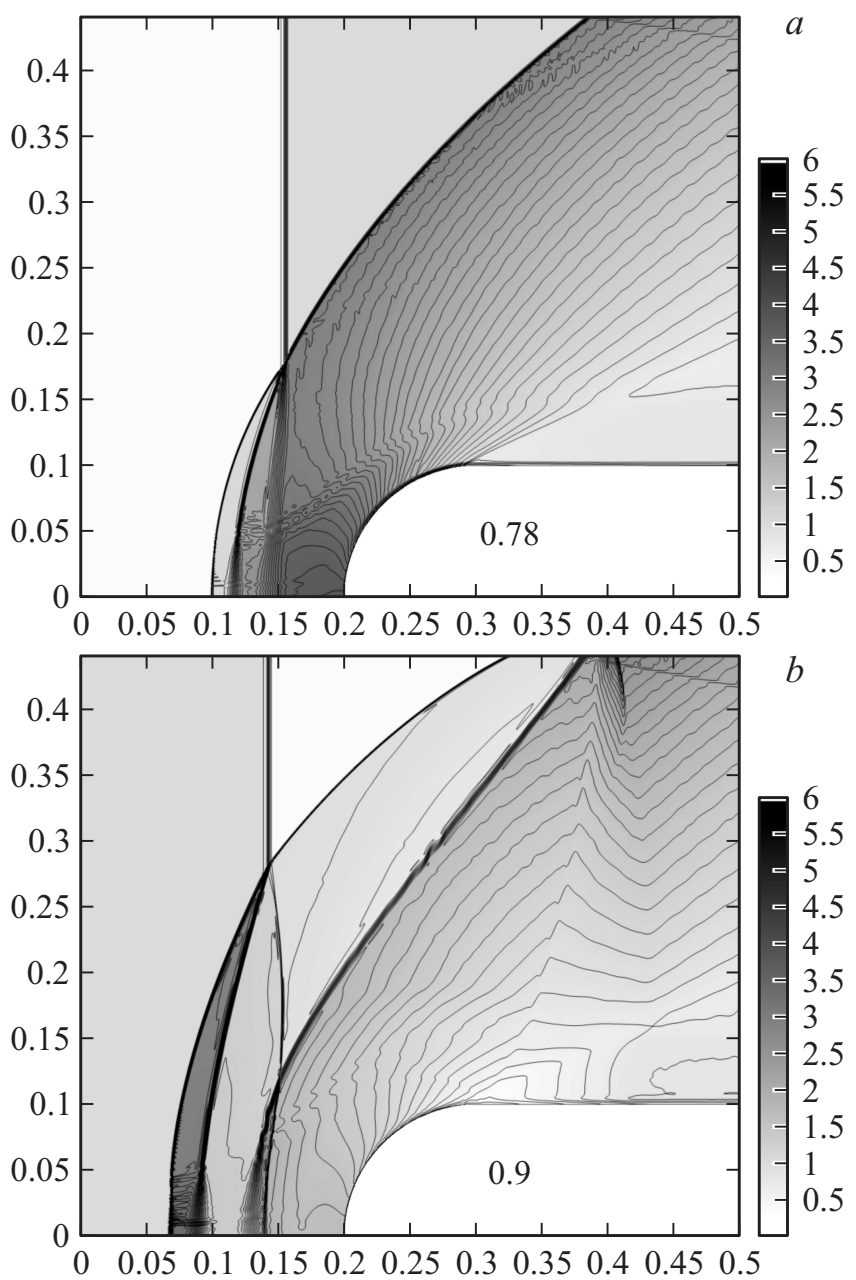

Рис. 1. Образование ударно-волновых конфигураций при взаимодействии ударного слоя с границами нагретой области: $a-$ взаимодействие с передней границей; $b-$ взаимодействие с задней границей.

неравновесностью происходящих процессов и неоднородностью течения по пространству и времени. На рис. 3 также приведено сравнение

7 Письма в ЖТФ, 2017, том 43, вып. 8 

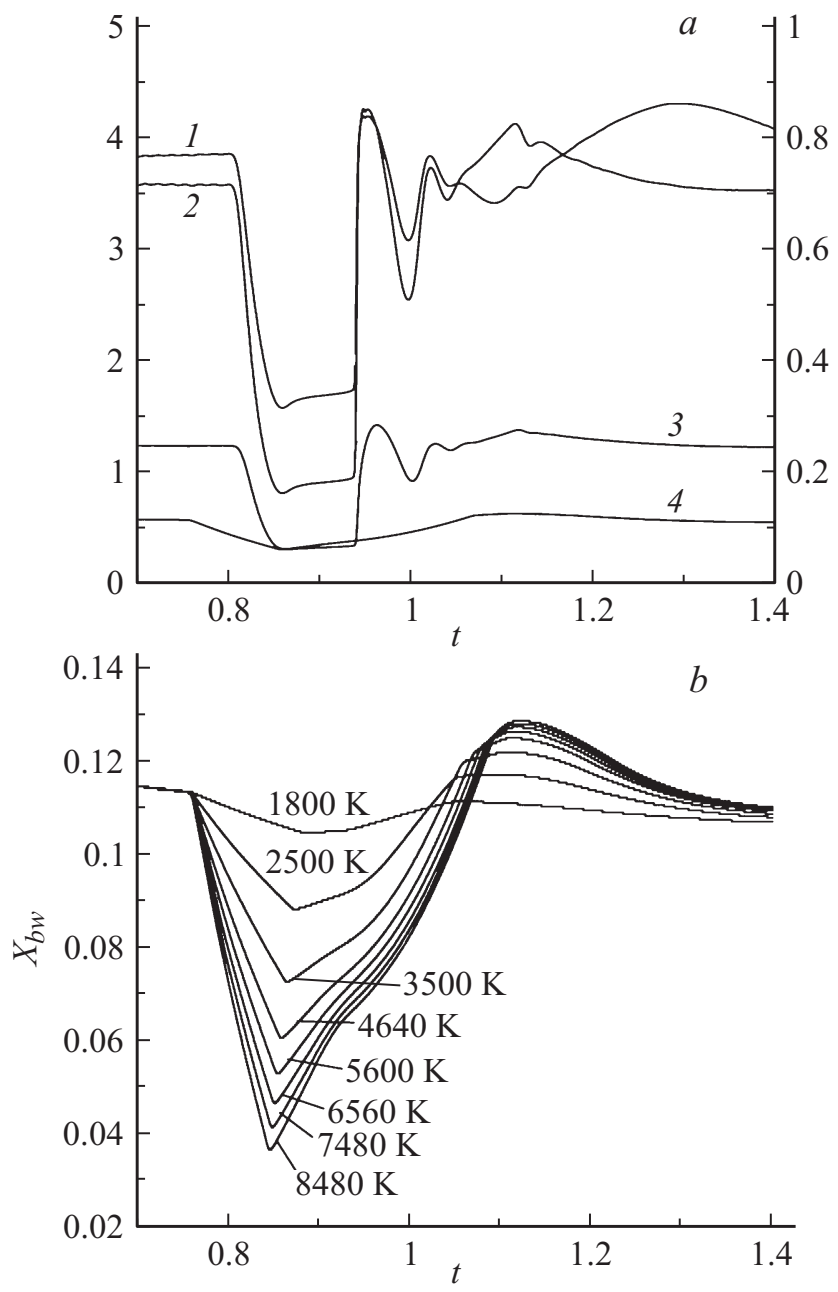

Pис. 2. Динамика исследуемых параметров: $a$ - плотность и давление в точке торможения (кривые 1,2 , левая ось), сила фронтального сопротивления (кривая 3) и координата головной ударной волны (кривая 4, правая ось); $b-$ координата головной ударной волны для различных значений температуры в тепловом слое. 


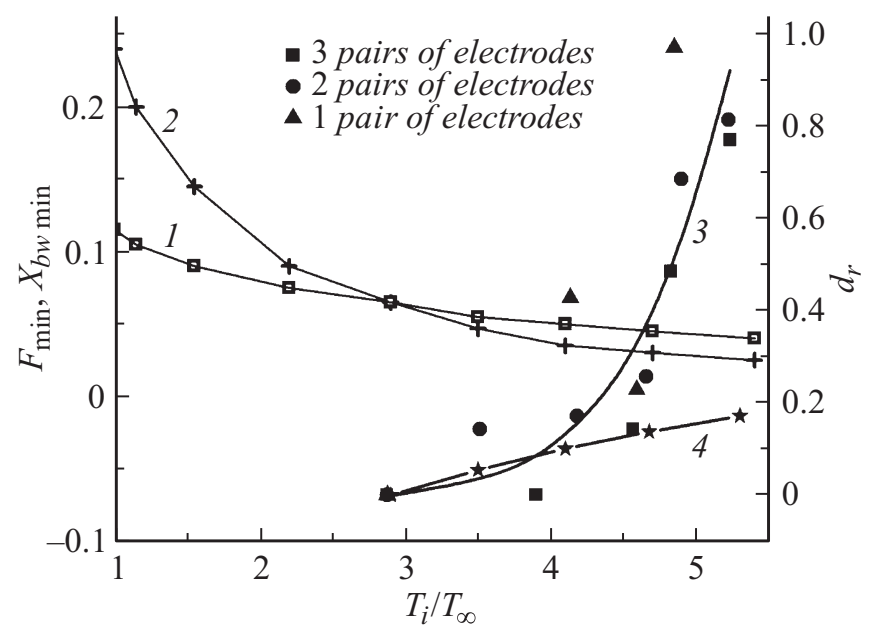

Рис. 3. Зависимость исследуемых параметров от относительной температуры источника: кривая 1 (левая ось) - минимальное значение координаты головной волны (расчет); кривая 2 (левая ось) - минимальная сила сопротивления фронтальной поверхности (расчет); кривая 3 (правая ось) - усредненная по всем экспериментальным значениям зависимость относительного расстояния от ударной волны до тела от степени неравновесности натекающего газа (здесь $T_{i}=T_{e}$ ); кривая 4 (правая ось) - максимальный относительный отход ударной волны от тела (расчет).

плазменного и теплового воздействия на величину относительного отхода головной ударной волны $d_{r}=\left(d-d_{0}\right) / d_{0}$ в зависимости от степени неравновесности газа $T_{e} / T_{\infty}$, получаемой в эксперименте. Здесь $d-$ расстояние между телом и головной ударной волной, $d_{0}-$ значение отхода головной ударной волны при температуре в источнике, равной начальной температуре электронов $T_{e 0}=4640 \mathrm{~K}$ [1]. Кривая $3-$ отход, полученный в эксперименте при обтекании тела неравновесной плазмой $\left(T_{i}=T_{e}\right)$, кривая $4-$ расчет при равновесном нагреве области потока до максимально возможной температуры газа $\left(T_{i}=T_{e}\right)$.

Из этих результатов можно сделать вывод, что в эксперименте сначала (при $T_{e} / T_{\infty}<4$ ) воздействие плазменных факторов, приводящих к возрастанию отхода головной ударной волны, незначительно. Далее, с ростом степени неравновесности (при $T_{e} / T_{\infty}>4$ ) это

$7^{*}$ Письма в ЖТФ, 2017, том 43, вып. 8 
воздействие начинает расти (с возрастающей скоростью), при этом значения относительного отхода существенно превышают полученные при воздействии на головную ударную волну однородной равновесной тепловой области потока. Данное сравнение показывает, что изменение положения ударной волны, полученное в эксперименте, обусловлено не только тепловым, а еще и дополнительным плазменным воздействием, механизм которого до конца неясен и связан, по всей видимости, с повышением температуры заряженных частиц и их взаимодействием с ударно сжатой ионизованной областью в ударной волне. Вероятно, эти процессы воздействуют на форму ударной волны, изменяя ее и придавая волне дополнительное ускорение. Заметим, что в результате волновое сопротивление тела понижается [14] (рис. 2,a,3). Поэтому можно констатировать также качественное отличие характера зависимости от степени неравновесности $T_{e} / T_{\infty}$ силы фронтального сопротивления тела от зависимости для случая равновесного однородного нагрева газа.

Сравнение расчетных и экспериментальных данных показало, что верхний предел теплового воздействия влияет на положение головной ударной волны слабее, чем плазменное воздействие. Таким образом, опираясь на расчеты взаимодействия полуограниченной тепловой области с ударным слоем, можно утверждать, что полученные в эксперименте данные указывают на существование в широком диапазоне температур эффекта плазменного воздействия на сверхзвуковое обтекание затупленного тела, который нелинейно возрастает с повышением степени неравновесности газа.

Соавторы Т.А. Лапушкина и О.А. Азарова благодарят за финансовую поддержку Российский фонд фундаментальных исследований, проекты № 15-01-04635 и 16-08-01228.

\section{Список литературы}

[1] Лапушкина Т.А., Ерофеев А.В., Поняев С.А., Бобашев С.В. // ЖТФ. 2009. T. 79. B. 6. C. 78-86.

[2] Лапушкина Т.А., Ерофеев А.В., Поняев С.А. // ЖТФ. 2011. Т. 81. В. 5. С. 28 34.

[3] Лапушкина Т.А., Ерофеев А.В., Поняев С.А. // ЖТФ. 2014. Т. 84. В. 7. С. 24 29.

Письма в ЖТФ, 2017, том 43, вып. 8 
[4] Jin J., Mursenkova I.V., Sysoev N.N. et al. // J. Flow Vis. Image Process. 2011. V. 18. N 4. P. 311-328.

[5] Bityurin V.A., Bocharov A.N., Tatarinov A.V. et al. // High Temperature. 2015. V. 53. N 5. P. 703-708.

[6] Благосклонов В.И., Минайлос А.Н. // Ученые записки ЦАГИ. 1972. Т. 3. № 2. C. $130-134$.

[7] Артемьев В.И., Бергельсон В.И., Немчинов И.В. и др. // МЖГ. 1989. № 5. C. $146-151$.

[8] Георгиевский П.Ю., Левин В.А. // МЖГ. 1993. № 4. С. 174-183.

[9] Azarova O.A., Knight D.D., Kolesnichenko Yu.F. // Shock Waves. 2011. V. 21. N 5. P. $439-450$.

[10] Азарова О.А. // ЖВМ и МФ. 2009. Т. 49. № 8. С. 1466-1483.

[11] Азарова О.А., Гвоздева Л.Г. // Письма в ЖТФ. 2016. Т. 42. В. 15. С. 59-66.

[12] Азарова О.А. // ЖВМ и МФ. 2015. Т. 55. № 12. С. 2067-2092.

[13] Рождественский Б.Л., Яненко Н.Н. Системы квазилинейных уравнений. М.: Наука, 1978. $687 \mathrm{c}$.

[14] Майкапар Г.И. // Ученые записки ЦАГИ. 1971. Т. 2. № 6. С. 23-31.

Письма в ЖТФ, 2017, том 43, вып. 8 